\title{
Drivers' risk profile indicates the need for a graduated driving licence in South Africa
}

\author{
L C Chokotho, R Matzopoulos, J E Myers
}

Background. Current driver mortality estimates do not consider the great differences in exposure across the population, giving a false impression that driver deaths are lowest in the youngest age group. Interventions to reduce risk among the younger age group include graduated driver licensing (GDL) - a three-phase licensing system for novice drivers consisting of a learner's permit, a provisional license, and a full license.

Objectives. We calculated driver fatality rates per 10000 registered drivers in each age group and assessed the need for stricter licensing conditions for novice and younger drivers.

Methods. Age-specific driver mortality rates were calculated using Western Cape Province 2008 mortuary data. The total number of licensed drivers in each age group served as the denominator. Incidence rate ratios were calculated using the age group of $65-79$ years as the reference. Chi-square test of trend on incidence rate ratios for the age groups was done. Statistical significance was set as $p<0.05$.

Results. There were 339 driver deaths; mean age was $39.4 \pm 13.8$ years, and males accounted for $80 \%$ of the deaths. Age-specific driver mortality rates were highest in the youngest age group (15 19 years). There was a significant progressive decrease (except for the age group $45-49$ years) in the risk of death from road traffic injuries with increasing age compared with the age group $\geq 65$ years (chi ${ }^{2}$ for trend $p<0.0001$ ).

Conclusion. This study showed a relationship between driver's mortality risk and younger age, and underscores the need for introduction of a GDL programme in South Africa.

S Afr Med J 2012;102(9):749-751. DOI:10.7196/SAMJ.5986
Road traffic injuries (RTIs) cause the death of more people aged 5 - 29 years than does HIV/AIDS. ${ }^{1}$ The World Health Organization predicts that, by 2030, RTIs will rise from the 9th (in 2004) to the 5th leading cause of death, while HIV/AIDS will drop from the 6th to the 10th ranking. ${ }^{2}$

In South Africa, injuries including RTIs are one constituent of the quadruple burden of disease, together with diseases related to poverty, chronic lifestyle diseases and HIV/AIDS. ${ }^{3}$ RTIs were ranked 9th among the leading causes of death in 2000, but the 5th leading cause of premature mortality and 4th leading contributor to the burden of disease as measured in disability adjusted life years (DALYs). ${ }^{4}$ The burden in Western Cape Province was $40 \%$ higher than the national figure. ${ }^{4}$

Drivers accounted for $29 \%$ of fatalities nationally, and $31 \%$ in the Western Cape Province. ${ }^{5}$ There have recently been calls in South Africa to introduce stricter licensing conditions for younger drivers in the form of graduated driver licensing (GDL), ${ }^{8,9}$ which is a threephase licensing system for novice drivers consisting of a learner's permit, a provisional license, and a full license. ${ }^{6}$ Although the exact requirements and the minimum holding periods for each level of GDL vary among countries, one common feature of the learner's permit phase is that learner drivers only drive under supervision of a fully licensed driver. ${ }^{7,10,11}$

Beit Cure Hospital, Blantyre, Malawi

L C Chokotho, MB BS, FCS (ECSA), MPH

School of Public Health and Family Medicine, University of Cape Town, and Burden of Disease Research Unit, Medical Research Council, Cape Town R Matzopoulos, BBusSci, MPhil (Epidemiology)

Centre for Occupational and Environmental Health Research (COEHR), School of Public Health and Family Medicine, Health Science Faculty, University of Cape Town J E Myers, BSc, MB ChB, DTM\&H, MD

Corresponding author: L Chokotho (namayombodr@yahoo.co.uk)
Other restrictions that might be directed at learner drivers include a zero blood alcohol content limit, restrictions on night-time driving, limiting the number of passengers, and requiring compulsory use of seat belts for all vehicle occupants. ${ }^{710,11}$ The provisional license phase allows unsupervised driving but also with restrictions for a specified period of time, and a full license is then only granted after successful completion of the prior phases.

Current estimates of RTI risk in South Africa are expressed as injuries or deaths per 10000 motor vehicles or per 100000 population for specific time periods. ${ }^{5}$ Young drivers are considered to constitute a particularly high-risk group, ${ }^{6,7}$ but the true nature of the risk is not usually appreciated because of the use of an inappropriate denominator. Fatality or injury estimates expressed as counts tend to under-represent the risk associated with young drivers, who comprise a relatively small proportion of the total driving population. To portray fatality risks more accurately, we calculated age-specific driver fatality rates per 10000 registered drivers, and assessed whether stricter licensing conditions for novice and younger drivers are needed.

\section{Methods}

RTI mortality data in Western Cape Province for 2008 were extracted from the database of the Department of Health's Forensic Pathology Service. This provided data from the 18 provincial mortuaries that collect information on all injury-caused deaths including those that are road traffic related. South Africa's strict medico-legal legislation requires that all non-natural deaths should be examined by a district surgeon, forensic pathologist or medical practitioner, ${ }^{12}$ and hence it was assumed that mortuaries can provide full coverage of all nonnatural deaths in the province.

Age-specific driver mortality rates were calculated using the total number of licensed drivers in each age group in Western Cape Province obtained from the electronic National Traffic Information System as denominators. ${ }^{13}$ The data were categorised by 5 -year intervals to the age of 64 years, with an additional category for drivers $\geq 65$ years old.

Descriptive analysis of demographic characteristics and calculation of incidence rate ratios were done using STATA version 10.0. ${ }^{14}$ Rate ratios used the age group $65-79$ years as the reference category, 
and incidence rate ratios in each age group were compared with the reference category. Comparison of incidence rate ratios between adjacent age groups was also done. A chi-square test of trend on incidence rate ratios for the age groups was done. Statistical significance was set as $p<0.05$.

Ethics approval to conduct the study was obtained from the University of Cape Town's Ethics Committee (HREC REF:295/2010) and approved by the Western Cape Department of Health's Provincial Health Research Committee.

\section{Results}

There were 339 driver deaths in 2008 with a mean age of $39.4 \pm 13.8$ years, with males accounting for $80 \%$ of the deaths. Calculation of age-specific mortality rates among motor vehicle drivers using the total number of licensed drivers in each age group as the denominator demonstrated the considerably higher rates among younger drivers (Fig. 1).

Fig. 1 provides a clearer representation of increased fatality risk among young drivers than the counts data in Fig. 2, which shows the least number of driver fatalities in the youngest age group.

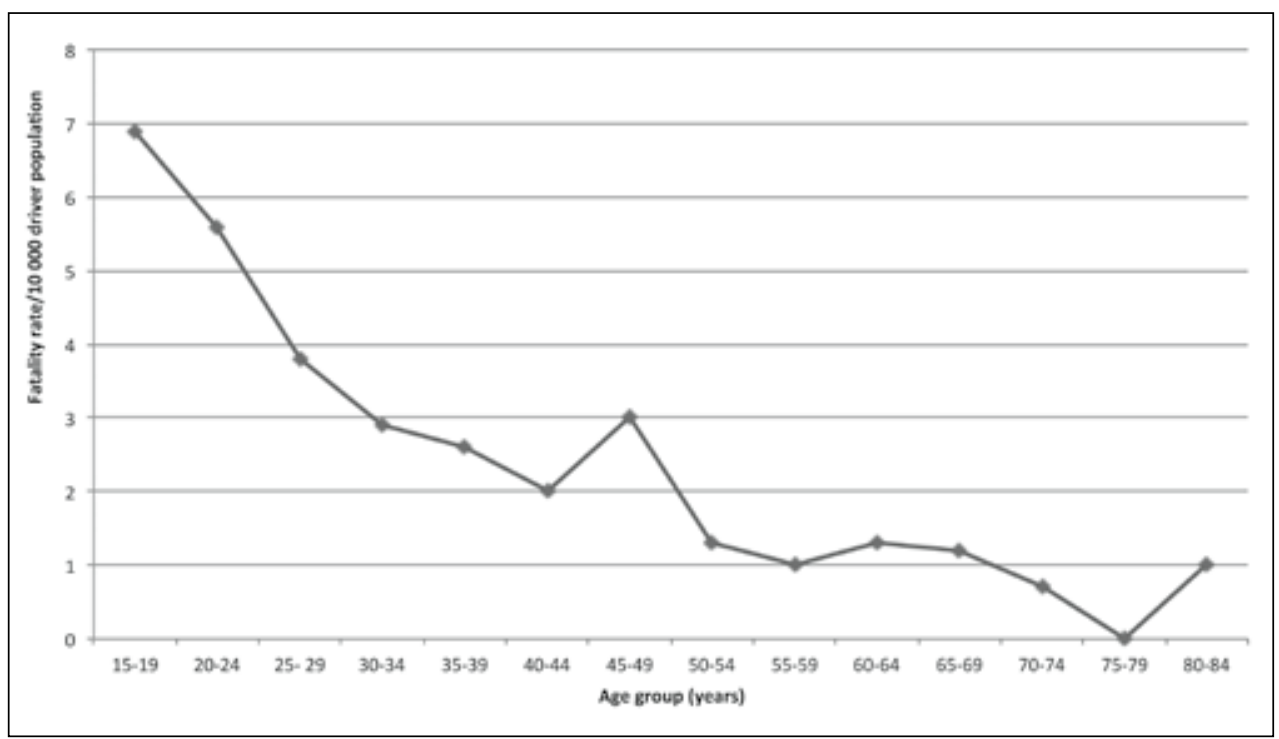

Fig. 1. Age-specific driver fatality rate per 10000 registered drivers.

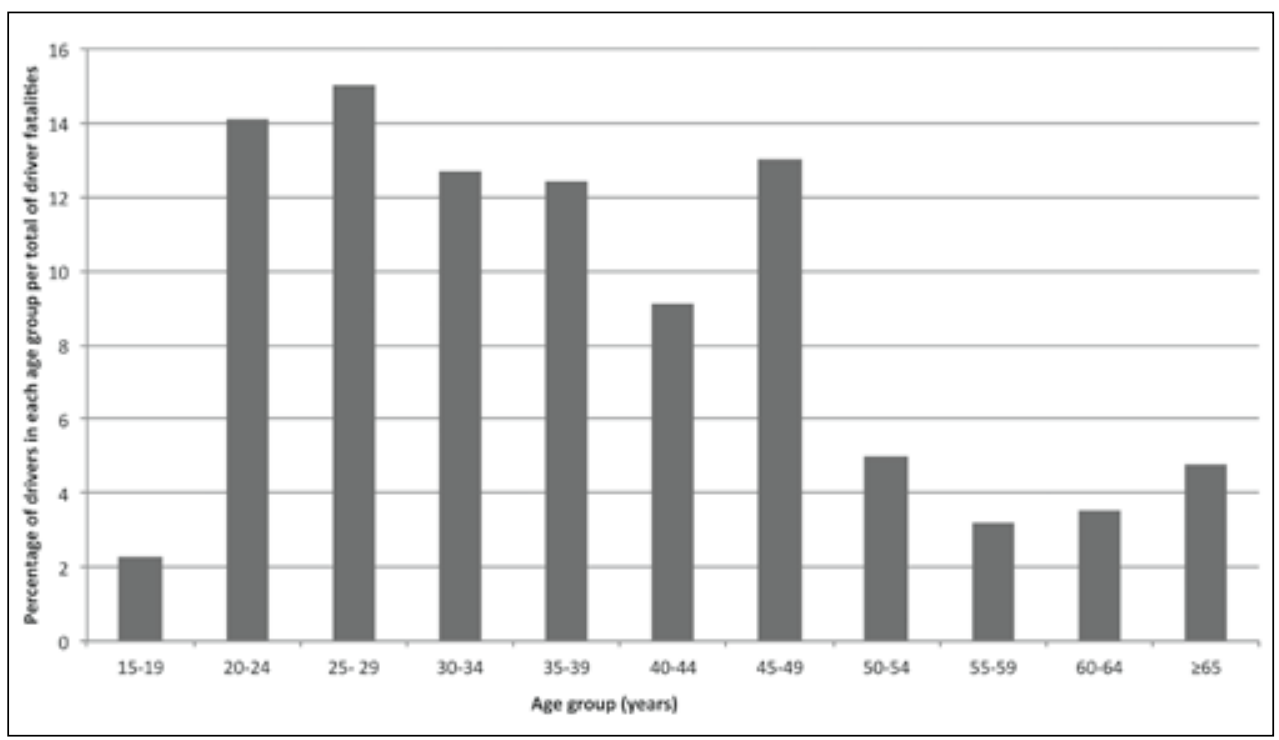

Fig. 2. Driver fatalities by age.
Table 1 shows that there is an overall progressive decrease (except for the age group 45 - 49 years) in the relative risk of death from a RTI with increasing age compared with the age group $\geq 65$ years. This trend was statistically significant $\left(\mathrm{chi}^{2}\right.$ for trend $\left.p<0.0001\right)$.

Only incidence rate ratios between adjacent age groups $45-49$ and 50 - 54 years were significantly different $(p=0.002)$. Comparison of incidence rate ratios between the other adjacent age groups did not reach statistical significance.

\section{Discussion}

This study has found definite decreasing age-specific mortality rates and risks of death with increasing age among drivers. The graduated driving license (GDL) is an intervention that has been implemented in some countries to reduce crash rates and resulting higher mortality rates in the younger age group. The increased crash rates among young drivers have been attributed to a combination of several factors including immaturity, inexperience in recognising risky situations, and risk-taking behaviour. ${ }^{7}$ The GDL therefore aims to reduce fatalities by increasing the opportunity for young, inexperienced drivers to obtain more supervised driving experience and limit their exposure to risky driving situations. ${ }^{10}$ The significant decreasing trend in risk of death among drivers with increasing age found in this study is striking, which clearly indicates the need for an intervention such as a GDL programme that targets the younger age groups in South Africa to offset the trend. The specific requirements and restrictions at each level of GDL must be agreed upon, depending on the risk factor profile of traffic deaths and availability of resources in South Africa. Since inexperience and immaturity of novice drivers also expose other road users (e.g. passengers and pedestrians) to increased risk of traffic-related injuries, reducing crash risk among younger drivers as a result of a GDL programme will also reduce crash risk for other road users.

Many GDL programmes in the USA and other countries have demonstrated their efficacy in reducing youngest drivers' risk of death by $20-40 \%$ regardless of their specific details. ${ }^{7}$ The benefits of GDL are clear as some evaluations have found reduced crash rates among novice drivers of all ages - not only teenagers - and also that drivers who began driving under a GDL system have lower crash rates in later years than similar-age nonGDL drivers. ${ }^{15}$ 
Table 1 . Relative risk of death using age group $\geq 65$ years as the reference group

\begin{tabular}{|c|c|c|c|}
\hline Age group (years) & Incidence rate ratio & Confidence interval & $p$-value ${ }^{*}$ \\
\hline $15-19$ & 7.0 & $2.9-16.8$ & $<0.0001^{\dagger}$ \\
\hline $20-24$ & 5.7 & $3.1-10.4$ & $<0.0001^{\dagger}$ \\
\hline $25-29$ & 3.8 & $2.1-7.0$ & $<0.0001^{\dagger}$ \\
\hline $30-34$ & 3.0 & $1.6-5.5$ & $0.0003^{\dagger}$ \\
\hline $35-39$ & 2.7 & $1.4-4.9$ & $0.0014^{\dagger}$ \\
\hline $40-44$ & 2.0 & $1.0-3.8$ & $0.04^{\dagger}$ \\
\hline $45-49$ & 3.0 & $1.6-5.6$ & $0.0002^{\dagger}$ \\
\hline $50-54$ & 1.3 & $0.6-2.7$ & 0.49 \\
\hline $55-59$ & 1.0 & $0.4-2.2$ & 0.99 \\
\hline $60-64$ & 1.3 & $0.6-2.8$ & 0.51 \\
\hline$\geq 65$ & Reference & & \\
\hline
\end{tabular}

Denominators used to calculate commonly used road traffic accident indicators such as injuries or deaths per 10000 motor vehicles or per 100000 population for specific time periods, are considered as reasonable measures of the population exposed to the risk of death from a traffic accident during the same time period in which injuries or deaths in the numerator occurred. ${ }^{16}$ However, these are crude measures because of the vast differences in exposure across the population. For instance, the denominator for deaths per 100000 population includes other people who are not on the roads; and not all inhabitants are exposed throughout the year. ${ }^{16}$ Therefore it is necessary to account for this in the denominator - but this is difficult to measure. Similarly, age-specific driver mortality 'rates' calculated by using the total population in a specific age group as the denominator do not provide an accurate risk profile because not all people in that particular age group are drivers, and therefore do not have the same exposure as those in the numerator. Drivers in the younger age groups also comprise a relatively small proportion of the total population in their specific age group. These factors result in an inflated denominator and an apparent low risk of death from RTIs. The importance of using an appropriate denominator when assessing risk was portrayed in this study in that when the actual number of drivers at risk was used as a denominator in calculating the age-specific mortality rate estimates, the higher risk in younger age groups became apparent. This is in contrast to Fig. 2, where counts were used as estimates of deaths in each group, and shows how misleading simple count data can be.

Driver fatality data are usually presented without considering the underlying population at risk, giving a wrong impression that driver deaths are lowest in the younger age group. ${ }^{17,18}$ The study has therefore highlighted the importance of using a proper epidemiological approach that compares like with like where the actual population at risk constitutes the denominator, in calculating age-specific mortality rates and risk ratios. This approach should be used throughout where possible in analysing traffic fatality statistics pertaining to motor car and truck or motorcycle drivers.

A limitation of this study is that the results did not take into account the influence of other risk factors associated with increased risk of death among drivers such as high blood alcohol concentration or use of seat belts, as such data were not routinely available. Lack of data is a major shortcoming of official road traffic surveillance systems in South Africa, and there is an urgent need to improve these. ${ }^{19}$ Another limitation is that we used age as a proxy for driving experience. Therefore, even though our choice of the denominator was more revealing of the increased risk of death among younger drivers than older ones, the results could be improved further by stratifying according to actual years of driving experience, and looking at other measures of exposure such as kilometres travelled. In the absence of reliable data for unlicensed drivers, we have also assumed that the age profile of unlicensed drivers is similar to licensed drivers and that the association between driving experience and crash risk would be consistent for licensed and unlicensed drivers. Notwithstanding these limitations, this study has provided a fruitful description of driver's mortality risk by age and has shown the need for introduction of a GDL programme in South Africa to reduce the risk of death among younger drivers.

\section{References}

1. Global Burden of Disease. Injuries and Violence: The Facts. Geneva: World Health Organization Global Burden of Disease, 2004. http://www.who.int/violence_injury_prevention/key_facts/VIP_key_ facts.pdf (accessed 17 March 2011)

2. World Health Organization. World Health Statistics 2008. Geneva: World Health Organization, 2008 http://www.who.int/whosis/whostat/2008/en/index.html (accessed 17 March 2011).

3. Bradshaw D, Schneider M, Dorrington R, Bourne DE, Laubscher R. South African cause-of-death profile in transition - 1996 and future trends. S Afr Med J 2002;92:618-623.

Bradshaw D, Groenewald P, Laubscher R, et al. Initial burden of disease estimates for South Africa 2000. S Afr Med J 2003;93:682-688.

. Road Traffic Management Corporation. 2008 Road Traffic Report. http://www.arrivealive.co.za/pages. aspx?i=2826 (accessed 15 January 2011).

. McKnight AJ, Peck RC. Graduated driver licensing: what works? Inj Prev 2002;8(Suppl II):ii32-ii38.

Hedlund J, Shults RA, Compton R. What we know, what we don't know, and what we need to know Hedlund J, Shults RA, Compton R. What we know, what we

about graduated driver licensing. S Safety Res 2003;34:107-115.
Driver's licence may take up to four years. Times Live [Internet], 15 Oct 2011. http://www.timeslive. Driver's licence may take up to four years. Times Live [Internet], 15 Oct 2011. http://www.times
co.za/local/2011/10/15/drivers-licence-may-take-up-to-four-years (accessed 10 December 2011).

9. Ndebele calls for graduated driver's licenses, Eye Witness News [Internet], 18 March 2012. http:// www.ewn.co.za/en/2012/03/18/Ndebele\%20calls\%20for\%20graduated\%20drivers\%20licenses.aspx (accessed 1 May 2012)

0. Morrisey MA, Grabowski DC, Dee TS, Campbell C. The strength of graduated drivers license programs and fatalities among teen drivers and passengers. Accid Anal Prev 2006;38:135-141.

11. Zhao J, Mann RE, Chipman M, Adlaf E, Stoduto G, Smart RG. The impact of driver education on self reported collisions among young drivers with graduated license. Accid Anal Prev 2006;38:35-42.

12. Republic of South Africa. Inquests Act. Act No. 58, Vol. 58. Cape Town, Government of South Africa, 1959.

3. eNATIS. Licensed Drivers Statistics (2010).

14. StataCorp. Stata Statistical Software: Release 10. College Station, TX, USA: StataCorp, 2007.

15. Begg D, Stephenson S. Graduated driver licensing: the New Zealand experience. J Safety Res 2003;34:99-105.

16. Bangdiwala SI, Anzola-Perez E, Glizer IM. Statistical considerations for the interpretation of Bangdiwala SI, Anzola-Perez E, Glizer IM. Statistical considerations for the interpretation of
commonly utilized road traffic accident indicators: implications for the developing countries. Accid Anal Prev 1985;17(6):419-427.

17. Butchart A, Peden M, Matzopoulos R, et al. The South African national non-natural mortality surveillance system - rationale, pilot results and evaluation. S Afr Med J 2001;91(5):408-417.

18. Lerer LB, Matzopoulos RG, Phillips R. Violence and injury mortality in the Cape Town metropole. $S$ Afr Med J 1997;87:298-301.

19. Chokotho L, Matzopoulos R, Myers JE. Assessing quality of existing data sources on road traffic injuries (RTIs) and their utility in informing injury prevention in the Western Cape Province, South Africa. Traffic Inj Prev (in press).

Accepted 16 July 2012. 